\title{
Assessment of Relationship between Effective Traits on Yield and Citral Content of Lemon Balm (Melissa officinalis L.) Populations using Path Analysis
}

\author{
Saeid Aharizad ${ }^{1 *}$, Mohammad Hasan Rahimi ${ }^{1}$, Mahmoud Toorchi' ${ }^{1}$ and Nasser Mohebalipour ${ }^{2}$ \\ 1 Department of Plant Breeding and Biotechnology, Faculty of Agriculture, University of Tabriz, Tabriz, Iran \\ ${ }^{2}$ Department of Agronomy and Plant Breeding, Faculty of Agriculture, Miyaneh branch, \\ Islamic Azad University, Miyaneh, Iran
}

\begin{abstract}
Lemon balm (Melissa officinalis L.) is one of the most important medicinal plants in the world trade that contains essential oils and has many applications in drug and flavoring industrials. In this study the relationships between the effective characters on yield, citral content and morphological traits in nine Iranian lemon balm populations and two populations from Germany and Japan were assessed in field conditions. Path analysis was performed on plant characters of 11 lemon balm populations to determine for essential oils yield, the direct and indirect effects of the following traits: essential oils percentage, citral content, plant height, number of tiller, chlorophyll index, number of nodes, stem diameter, leaf length, leaf width, leaf area index (LAI), total fresh weight, fresh weight of leaves in the lower a second of plant (L1f), fresh weight of leaves in the upper a second of plant (L2f), fresh weight of stems in the lower a second of plant (S1f), fresh weight of stems in the upper a second of plant (S2f), total dry weight, dry weight of leaves in the lower a second of plant (L1d), dry weight of leaves in the upper a second of plant (L2d), dry weight of stems in the lower a second of plant (S1d), dry weight of stems in the upper a second of plant (S2d) and dry/fresh weight ratio. Essential oils yield was significantly correlated with the leaf width, essential oils percentage and citral content. The result of path analysis showed that essential oil percentage and leaf width had the highest and lowest direct effect on essential oil yield in the assessed populations, respectively. Using these results, breeders can collect plants with high shoot yield, in order to select plants with high essential oil.
\end{abstract}

Keywords: Lemon Balm, Path Analysis, Essential Oils Yield, Morphological Traits.

\section{Introduction}

Lemon balm (Melissa officinalis L.) is a medicinal plant and native to southern Europe, northern Africa, east as far as the Caucasus and northern (Bagdat, 2006). Due to the several applications in pharmacy, nutritional and sanitary industrials, lemon balm was one of the most important commercial plants during the recent decades. This plant occurs naturally in sandy and scrubby area $[6,8]$.

Lemon balm is used for several purposes such as an additive in food, an herb tea, an ingredient in cosmetics, an ornamental and a medicine. This plant has traditionally been used to treat catarrh, fever, flatulence, headaches, influenza and toothaches. It also has sedative, antidepressant, antiviral, antibacterial and antispasmodic effects $[3,7]$. Although over 100 chemicals have been identified in Melissa officinalis L. (Duke, 2006), Major components are citral (neral + geranial) representing $48 \%$ of the essential oil, followed by citronellal with $39.47 \%$ and $\beta$-caryophyllene with $2.37 \%$ [5]. Patora et al. [2] revealed that essential oils percentage of 16 populations collected from several regions of Poland was $0.060 .167 \%$.

* Corresponding author:

Saeid Aharizad (s.aharizad@yahoo.com) 
Path coefficient analysis has been used to obtain selection criteria in several crops. This technique measures the direct influence of one variable on another and also separates this correlation coefficient into components of direct and indirect effects. Talle et al. [4] evaluated the effective traits on yield and compounds of essential oils and morphological traits in six lemon balm accessions which gathered from different provinces of Iran. They reported that shoot yield had the highest direct effect on essential oil yield in the assessed accessions. Furthermore, leaf length, leaf width and dried stem weight had the lowest direct effect on essential oil yield. Mirzaie-Nodoushan et al. [1] stated that the percentage of leaf essential oil and leaf length had a high direct effect on the dependent variable, flower essential oil yield. They also reported that stem diameter and flower essential oil yield had almost equal positive direct effects on leaf essential oil yield. Investigation of effective traits on essential oil in two ecotypes of Mentha (Mentha longifolia L.) using path analysis indicated that leaf oil yield and flower oil percentage had a high direct effect on total essential oil yield (Abaszadeh et al. 2011).

Plant material consisted of 11 lemon balm (L.) populations including nine Iranian wild populations, namely Karaj, Ardabil, Esfahan, Hamadan, Fars, Qazvin2, Qazvin3, Kurdistan, and two improved cultivars from Germany and Japan (Figure 1). Seeds of Iranian landraces were provided by Iranian Forests and Rangelands Research Institute, and seeds of improved cultivars were obtained from Iranian Institute of Medicinal Plants. The experiment was carried out based on randomized complete block design (RCBD) with three replications in Tabriz Agriculture Research Station (Karkaj), Tabriz, Iran (1360 m altitude). Lemon balm seedlings were transplanted with $50 \mathrm{~cm}$ row space and $30 \mathrm{~cm}$ apart in the row. The experiment was irrigated every week. Five plants on the rows in each plot were cut in the early stages of flowering and 22 morphological traits were scored. To determine the essential oils content, a sample of 20 gram dried herb was powdered and mixed with $1000 \mathrm{ml}$ of distilled water in flask, and the water was distilled for 175 min using a Clevenger-type apparatus. The oils were dried over sodium sulphate and its rate was measured in $\mathrm{ml}$ oil per $20 \mathrm{~g}$ dry matter of herb and converted to the essential oils percentage. Samples were kept in glass containers with plastic lid in refrigerator, until the absorbance of citral content was measured at $237 \mathrm{~nm}$ with a spectrometer (WPA model S2100).

A diagram of the path analysis of the data regarding leaf essential oil and its correlated characters is presented in Figure 2. The direct, indirect and the total influences of the independent variables including citral content, leaf width, leaf length, number of tiller, total dry weight and L1d on the dependent variable, essential oil percentage, are presented in Table 3. The citral content, leaf width and total dry weight had almost positive direct effects on essential oil percentage. In contrast, number of tillers, leaf length and L1d showed a negative direct effect on essential oil percentage. The absolute value of direct effect from the number of tillers was approximately twice of the same from leaf length. Regarding indirect effects, despite a negative direct effect, leaf length had a positive indirect effect on the leaf

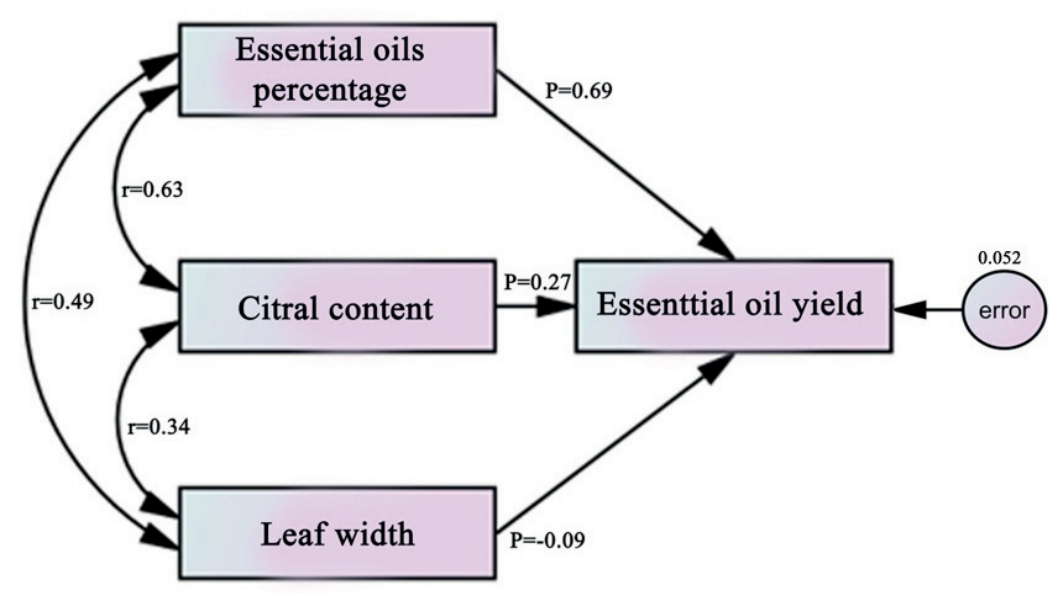

Figure 1. Path diagram showing interrelationship among the dependent variable, essential oil yield and the independent variables, leaf width, essential oil percentage and citral content in lemon balm (Melissa officinalis L.) populations. 


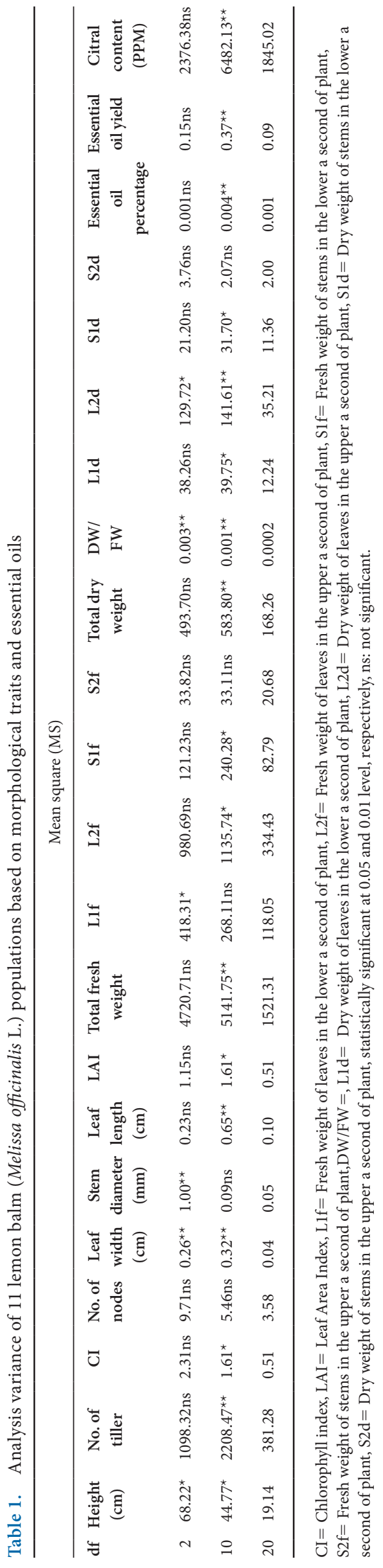




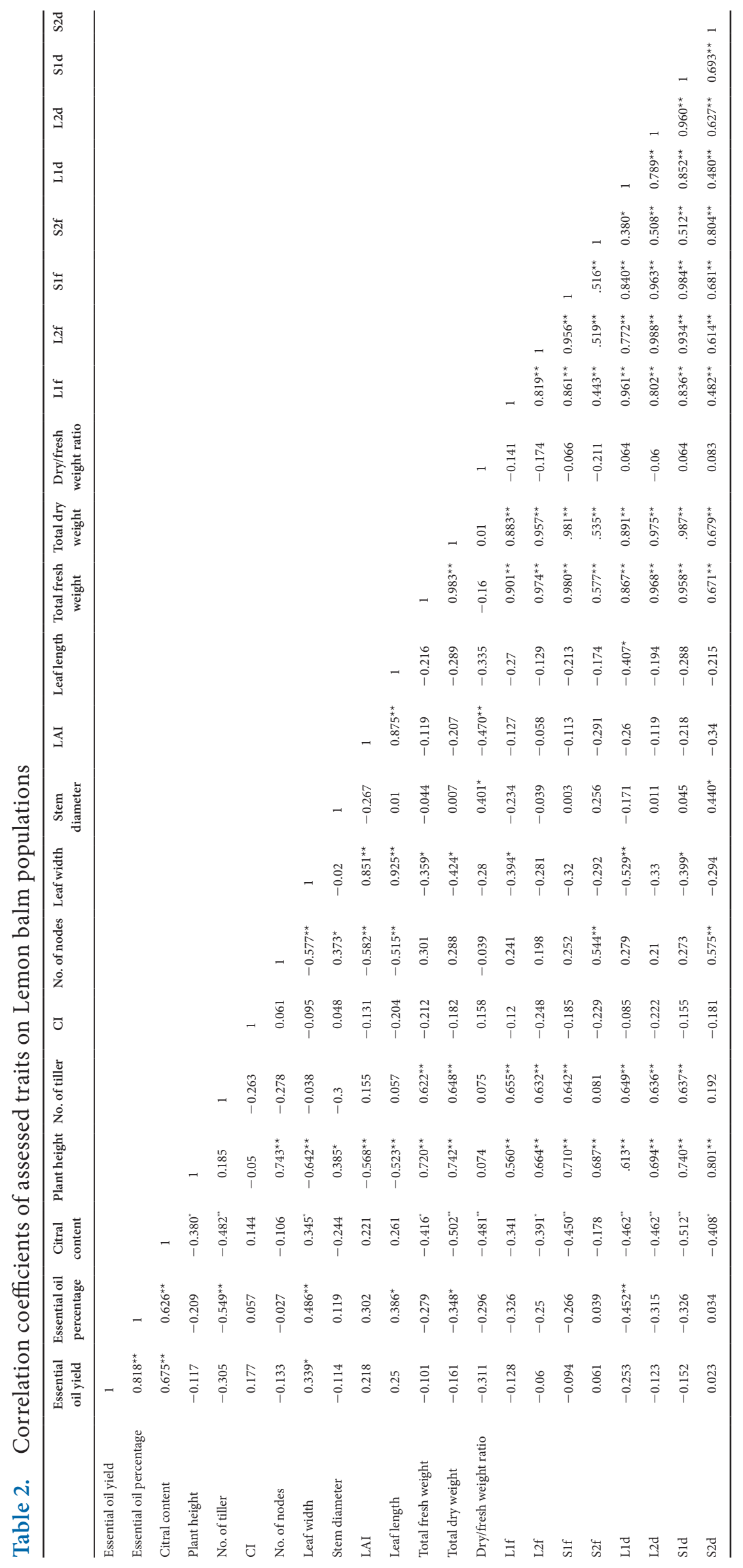


essential oil yield through three independent variables (citral content, leaf length and L1d). Negative direct effect of leaf length $(-0.25)$ deteriorated its highly positive total indirect effect (0.734), resulting to a total effect of 0.386 . Total dry weight showed a little positive indirect effect on essential oil percentage through leaf length. The most indirect effect on essential oil percentage belonged to leaf length indirect effect through leaf width.

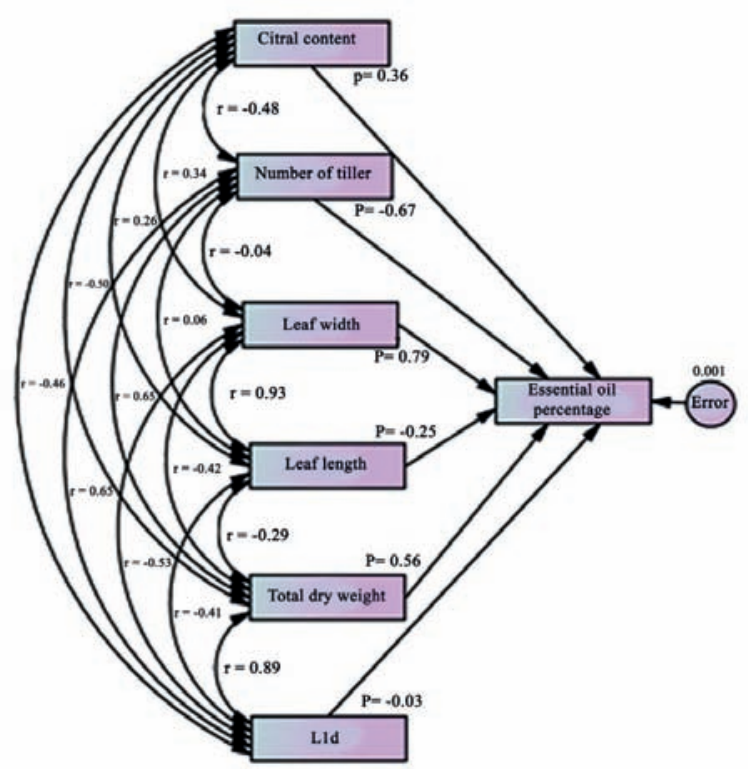

Figure 2. Path diagram showing interrelationship among the dependent variable, essential oil percentage and the independent variables, citral content, number of tiller, leaf length, leaf width, total dry weight and L1d (dry weight of leaves in the lower a second of plant) in lemon balm (Melissa officinalis L.) populations.
A diagram describing the path analysis of the data regarding the essential oil yield and its correlated characters is shown in Figure 2. This diagram indicates direct and indirect pathways of influence of independent variables, leaf width, citral content and essential oil percentage on essential oil yield. Among the independent characters, essential oil percentage had the greatest direct effect on essential oil yield (Table 4). Leaf length also had a high direct effect on the essential oil yield. The indirect effect of citral content on essential oil yield was negative through leaf width. This character relationship was similar to the first analysis, in which citral content direct and indirect effects on essential oil percentage were mainly positive. One remarkable point is that leaf width had direct negative effect on essential oil yield but it increased the essential oil yield indirectly. Leaf width and citral content had a great indirect effect through percentage essential oil, indicating that increase in leaf width and citral content would cause high essential oil yield through increasing essential oil percentage. Essential oil percentage and citral content had little negative indirect effect on essential oil yield through leaf width (0.044 and 0.030 , respectively). Most of the total indirect effects of the independent variables on essential oil yield are positive and the only negative effect is negligible.

Essential oil yield can be increased in lemon balm by indirect selection through the correlated characters, such as leaf width, leaf length and dry matter. In other words, selection for phenotypic characters could be used to improve a chemical character. However, leaf width with positive direct and indirect effects on essential oil per-

Table 3. Correlations ( $r$ ), direct path coefficients, and indirect path coefficients between dependent variable, essential oil percentage, and independent variables, citral content, leaf width, leaf length, number of tiller, total dry weight and L1d.

\begin{tabular}{|c|c|c|c|c|c|c|c|c|}
\hline \multirow{2}{*}{$\begin{array}{l}\text { Independent } \\
\text { variable }\end{array}$} & \multirow{2}{*}{$\begin{array}{c}\text { Correlation } \\
\text { with essential } \\
\text { oil percentage }\end{array}$} & \multirow{2}{*}{$\begin{array}{l}\text { Direct effect of } \\
\text { the independent } \\
\text { variable }\end{array}$} & \multicolumn{6}{|c|}{ Indirect effect of the independent variable on essential oil percentage } \\
\hline & & & $\begin{array}{c}\text { Citral } \\
\text { content }\end{array}$ & $\begin{array}{c}\text { Number } \\
\text { of tiller }\end{array}$ & Leaf width & Leaf length & $\begin{array}{c}\text { Total dry } \\
\text { weight }\end{array}$ & L1d $^{\dagger}$ \\
\hline Citral content & 0.626 & 0.36 & - & 0.321 & 0.268 & -0.065 & -0.280 & 0.013 \\
\hline Number of tiller & -0.549 & -0.67 & -0.172 & - & -0.031 & -0.015 & 0.364 & -0.019 \\
\hline Leaf width & 0.486 & 0.79 & 0.122 & 0.026 & - & -0.232 & -0.235 & 0.015 \\
\hline leaf length & 0.386 & -0.25 & 0.093 & -0.040 & 0.734 & - & -0.162 & 0.012 \\
\hline total dry weight & -0.348 & 0.56 & -0.180 & -0.435 & -0.331 & 0.072 & - & -0.026 \\
\hline $\mathrm{L}^{1 d^{+}}$ & -0.452 & -0.03 & -0.165 & -0.435 & -0.418 & 0.102 & 0.498 & - \\
\hline
\end{tabular}

${ }^{\dagger} \mathrm{L} 1 \mathrm{~d}=$ dry weight of leaves in the lower a second of plant 
Table 4. Correlations ( $\mathrm{r}$ ), direct path coefficients, and indirect path coefficients between dependent variable, essential oil yield, and independent variables, leaf width, , essential oil percentage and citral content

\begin{tabular}{lccccc}
\hline $\begin{array}{l}\text { Independent } \\
\text { variable }\end{array}$ & $\begin{array}{l}\text { Correlation with } \\
\text { essential oil yield }\end{array}$ & $\begin{array}{l}\text { Direct effect of the } \\
\text { independent variable }\end{array}$ & \multicolumn{2}{c}{$\begin{array}{c}\text { Indirect effect of the independent variable } \\
\text { on essential oil yield }\end{array}$} \\
\cline { 4 - 6 } & & & $\begin{array}{l}\text { Essential oil } \\
\text { percentage }\end{array}$ & Citral content & Leaf width \\
\hline $\begin{array}{l}\text { Essential oil } \\
\text { percentage }\end{array}$ & 0.818 & 0.69 & - & 0.170 & -0.044 \\
$\begin{array}{l}\text { Citral content } \\
\text { Leaf width }\end{array}$ & 0.675 & 0.27 & 0.434 & - & -0.030 \\
\hline
\end{tabular}

centage, which is in turn the most influential character on essential oil yield, would be the best indicator of essential oils content in the lemon balm populations under study. Citral content with the net positive direct and indirect effects on essential oil yield is another important indicator of essential oil in these populations. Leaf width with indirect effects on these two traits increases the essential oil yield. These characters may be the main criteria for lemon balm breeders to employ an indirect selection for high essential oil yielding genotypes. Thus, for the populations under investigation, genetic improvement of the essential oil percentage, citral content and leaf width would have beneficial effects on essential oil yield. Therefore, indirect selection for high essential oil yield based on morphological characters would be valuable, particularly when a large number of populations are taking into account in early stages of a breeding program.

\section{References}

1. Mirzaie-Nodoushan H, Rezaie M B et al. (2001). Path analysis of the essential oil-related characters in Mentha spp. Flavour and Fragrance Journal, vol 16(5), 340-343.
2. Patora J, Majda T, et al. (2003). Variability in the content and composition of essential oil from lemon balm (Melissa officinalis L.) cultivated in Poland, Acta Polnise Pharmaceutica-Drug Research, vol 60(5), 395-400.

3. Simon J E, Chadwic A F et al. (1984). Herbs: An Indexed Bibliography, 1971-1980, The Scientific Literature on Selected Herbs, and Aromatic and Medicinal Plants of the Temperate Zone, Archon Books, Hamden, CT, USA.

4. Talle B, Darvish F. et al. (2012). Assessment of relationship between effective Traits on yield and compounds of essential oil and morphological traits of lemon balm (Melissa officinalis L.) accessions using path analysis and canonical correlation. Journal of Basic and Applied Scientific Research, vol 2(4), 3719-3723.

5. Tavares A C, pimento M C et al. (1996). Micropropagation of Melissa officinalis L. through proliferation of axillary shoots. Plant Cell Reports, vol 15(6), 441-444.

6. Tucker A O, and DeBaggio T (2000). The big book of herbs: a comprehensive illustrated reference to herbs of flavor and fragrance, Loveland, CO: Interweave Press.

7. Tyler V E. (1999). Herbs affecting the central nervous system. Janick J (Ed.), Perspectives on new crops and new uses, ASHS Press. Alexandria, VA, USA, 442-449.

8. Voigt CE. (2006). Lemon balm, not just a sweet smelling weed anymore, The herbarist, vol 72, 9-13. 